\title{
GERBANG LOGIKA BERBASIS PROGRAMMABLE LOGIC DEVICE (PLD)
}

\author{
Oleh: \\ Muhammad Irmansyah
}

Staf Pengajar Teknik Elektro Politeknik Negeri Padang

\begin{abstract}
In middle 1990, electronics industry had evolution in personal Computer, telephone cellular and high speed data communication equipment. To follow this development, electronics companies have designed and produce new product. One of these innovations is Programmable Logic Devices (PLD) technology. It is a technology to change function of IC digital logic using programming. Many of Programmable Logic Device (PLD) can be used to programming logic using single chip of integrated circuit (IC). Programmable Logic Devices (PLD) technology is applied using IC PAL 22 V10 to design basic logic gate $A N D, O R, N O T$ and combinational logic gate NAND and NOR.
\end{abstract}

Keyword: Programmable Logic Devices (PLD), logic gate, IC PAL 22 V10

\section{PENDAHULUAN}

Pada pertengahan 1990, industri elektronika sangat mengalami perkembangan dalam personal computer, telepon seluler dan peralatan komunikasi data dengan kecepatan tinggi. Untuk persaingan pasar, produsen membuat produk dengan meningkatkan fungsi, penampilan, biaya rendah, konsumsi daya yang rendah dan ukuran yang kecil. Untuk memenuhi kebutuhan ini, produsen menciptakan sistem yang komplek dengan pemakain IC yang lebih sedikit dan ukuran PCB yang lebih kecil. Berbagai teknologi terpadu digunakan seperti proses submikron semikonduktor, teknologi PCB, dan pemaksimalan penggunaan permukaan PCB. Penunjang design digunakan oleh para designer berupa Electronic Design Automation (EDA) tools. Kondisi pasar ini membuat metodologi modern dalam design dan tes digunakan, antara lain Programmable Logic Device (PLD).

Untuk mengikuti perkembangan ini, perusahaan elektronika telah mendesain dan membuat produk baru. Untuk memenuhi tuntutan ini, engineers dan teknisi berusaha untuk membuat penemuan yang membantu mereka membuat prototype rangkaian digital dan mengevaluasi kemajuannya dalam waktu yang lama. Salah satunya adalah teknologi Programmable Logic Devices (PLD) yang merupakan IC digital logic yang bisa dirubah fungsinya melalui pemrograman dan seperti diindustri, akan dapat dilihat bagaimana mudahnya membuat rangkaian digital menggunakan PLD.

Berbagai Programmable Logic Device (PLD) dapat digunakan untuk logika pemrograman yang banyak dengan hanya menggunakan satu IC. 
Keuntungannya

adalah

kefleksibelannya dalam penggunaan dengan skedul yang lebih ketat, untuk penggunaan pada produk dengan volume yang kecil dan untuk pengaktifan awal sebuah produk meskipun digunakan pada high volume.

\section{Perumusan Masalah}

Bagaimana merancang dan membuat gerbang logika berbasis Programmable Logic Device (PLD) menggunakan IC PAL 22V10.

\section{Tujuan}

Merancang dan membuat gerbang logika berbasis Programmable Logic Device (PLD) menggunakan IC PAL 22V10.

\section{Batasan Masalah}

1. Mengaplikasikan teknologi Programmable Logic Device (PLD) untuk gerbang logika gerbang AND, OR, NAND, NOR dan NOT.

2. Bahasa pemograman yang digunakan adalah Warp 4.2.

\section{Programmable Logic Device (PLD) Membuat rangkaian menggunakan PLD}

Single PLD terdiri dari gerbang logika dalam jumlah yang banyak, termasuk device penghubung dimana semua device ini berada dalam satu IC. Dengan menggunakan PC, logika program dapat dibuat dengan HDL menggunakan text editor atau gambar sederhana dari logika rangkaian dengan menggunakan schematic editor. HDL atau schematic selanjutnya decompile dengan program untuk membuat detail dari rangkaian logika yang akan menghasilkan output dari rancangan yang yang telah dibuat pada HDL atau skematik. Operasi dari rangkaian ini selanjutnya dapat disimulasikan untuk meyakinkan bahwa output sesuai dengan yang diinginkan. Jika simulasi rangkaian telah sesuai, maka desain selanjutnya didownload melalui parallel port ke PLD. Switch dihubungkan ke input dan LED ke output untuk mencoba test akhir pada prototype.

5 langkah yang dibutuhkan untuk membuat prototype menggunakan PLD: Step 1 :Buat rangkaian baru menggunakan schematic editor pada software

Step 2 : Compile rangkaian menjadi bitstream file, ketika file ini diload ke CPLD akan menghasilkan output yang sesuai dengan skematik yang diberikan

Step 3: Buktikan operasi dari rangkaian dengan menggunakan software fungtional dan timing simulator

Step 4 : Download file rangkaian daei PC ke PLD

Step 5: Test PLD secara pisik dengan mengaktifkan input dan melihat output yang dihasilkan

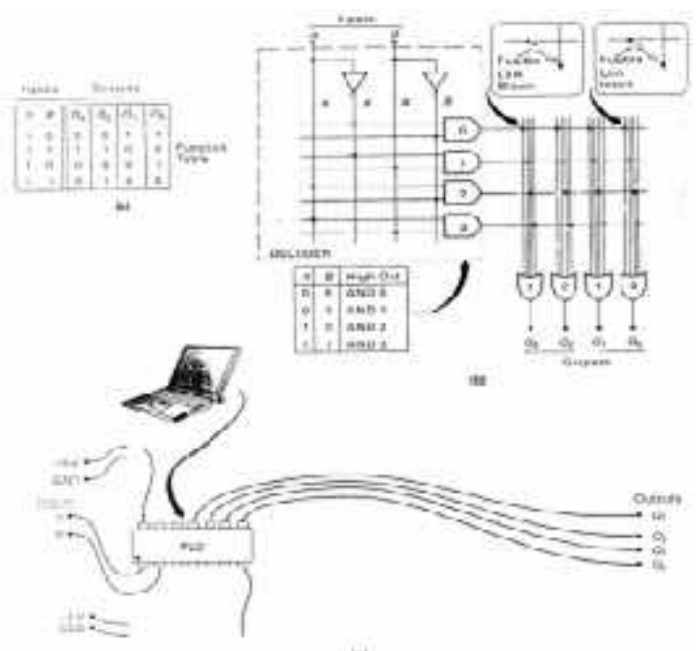

Gambar 1. Konstruksi rangkaian PLD

Salah satu contoh IC yang menggunakan teknologi PLD adalah IC22V10. IC $22 \mathrm{~V} 10$ terdiri dari 24 pin dengan pin 12 berfungsi sebagai ground dan pin 24 berfungsi sebagai catu daya 5 volt. Pin 1 berfungsi sebagai clock atau input dan pin 2 sampai 13 (kecuali pin 12) berfungsi sebagai input saja. Pin 14 sampai pin 23 berfungsi sebagai input atau output. 


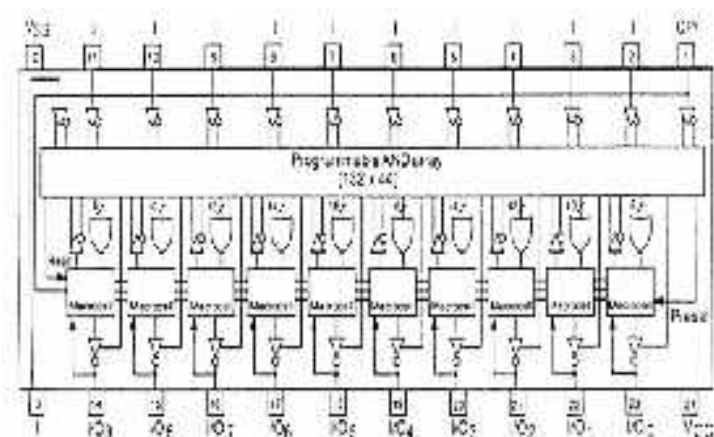

Gambar 2 Konfigurasi IC PAL 22V10

\section{Gerbang Logika}

Gerbang logika adalah rangkaian dasar yang mebentuk computer. Jutaan transistor di dalam mikroprosesor membentuk ribuan gerbang logika. Sebuah gerbang logika sederhana mempunyai satu terminal input. Keluarannya dapat tinggi/high (1) atau rendah/low (0), tergantung level digital yang diberikan pada terminal input. Di sini kita akan membahas 5 gerbang logika dasar saja, diantaranya: AND, OR, NAND, NOR, Inverter (NOT).

Gerbang logika yang kini sering dipakai berasal dari IC logika seperti $74 x x$ atau 40xx. Satu IC yang berisi $4-8$ gerbang loika kini hanya berharga beberapa ribu rupiah, namun IC yang dibuat dengan teknologi tinggi seperti prosesor Intel Pentium, memiliki berjuta-juta gegrbang logika, yang harga tiap gerbang logika menjadi hanya beberapa rupiah. Semua chip kompleks yang melakukan pemrosessan sinyal secara digital dapat dipastikan mengguanakan gerbang-gerbang logika pada detail desain rangkaiannya.

\section{Gerbang AND}

Gerbang AND memiliki dua masukan input yaitu input $A$ dan input B. Operasi dari gerbang ini sederhana, yaitu output $\mathrm{Y}$ atau keluaran $\mathrm{Y}$ akan mejadi 1 jika kedua syarat inputnya dalam keadaan 1. Jika salah satu dari isyarat masukannya 1, maka sinyal keluarannya tetap 0 . Dan bila kedua inputnya 0 maka outputnya akan 0 . Symbol dari gerbang AND dinyatakan pada gambar dibawah ini:

\section{Gerbang OR}

Gerbang OR memiliki dua masukan input dan satu isyarat keluaran output. Jika salah satu atau kedua isyarat masukannya 1, maka sinyal keluarannya adalah 1. Jika kedua masukannya yaitu masukan A dan masukan B adalah 0 maka keluarannya 0 . Simbol atau lambang dari gerbang logika OR dinyatakan pada gambar di bawah ini:

\section{Gerbang NAND}

Gerbang NAND merupakan gerbang logika kombinasi yang sama operasinya dengan gerbang dasar AND, tetapi pada bagian keluarannya dibalik dengan gerbang logika inverter (NOT).

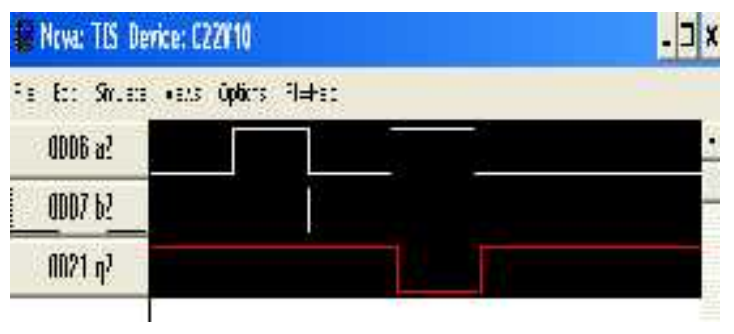

\section{Gerbang NOR}

Gerbang logika NOR adalah sebuah gerbang logika kombinasional yang sama operasinya dengan gerbang logika dasar OR, tetapi bagian outputnya dibalik dengan gerbang inverter (NOT).

\section{Gerbang NOT}

Gerbang logika inverter yang sering disebut gerbang logika NOT adalah sebuah gerbang logika yang memiliki hanya satu input dan hanya satu output, fungsinya sebagai pembalik. Prinsip kerja dari gerbang logika inverter sangat sederhana, yaitu apapun keadaan isyarat yang diberikan pada bagian input akan dibalik oleh gerbang logika ini sehingga 
pada bagian outputnya akan menjadi berlawanan, atau keadannya terbalik. Contohnya, jika pada inputnya keadaanya 1 maka keadaan keluarannya akan menjadi 0. Demikan juga jika pada bagian inputnya bernilai 0 maka keluarannya akan bernilai 1 . Dengan kata lain, isyarat outputnya adalah komplemen dari isyarat outputnya.

\section{Perancangan Perangkat Keras Diagram Blok Sistem}

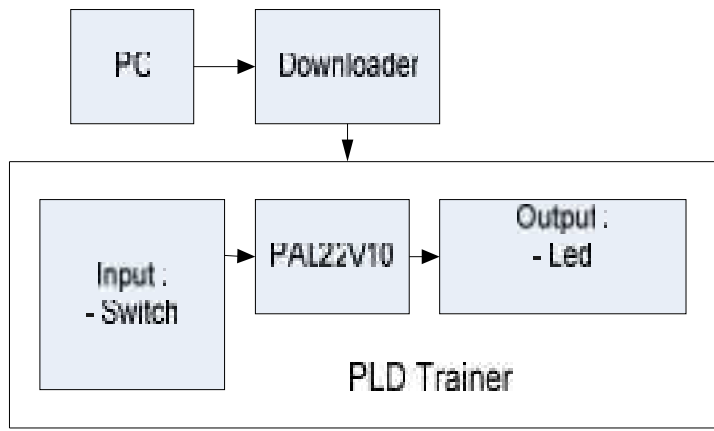

Gambar 3. Diagram blok hardware

1. Personal Computer (PC), berfungsi sebagai tempat pembuatan program dengan menggunakan bahasa pemograman Warp 4.2 dan simulasi hasil pemograman.

2. Downloader, berfungsi untuk memindahkan data hasil pemograman dari personal computer (PC) ke IC PAL 22V10.

3. Input switchberfungsi sebagai input logic.

4. PAL 22V10, merupakan salah satu jenis Programable Logic Device (PLD)

5. Output led berfungsi sebagai indikator output.

\section{Gerbang logika}

1. IC 7400 gerbang NAND 2 input

2. IC 7402 gerbang NOR 2 input

3. IC 7404 gerbang NOT

4. IC 7411 gerbang AND 2 input

5. IC 7421 gerbang OR 2 input

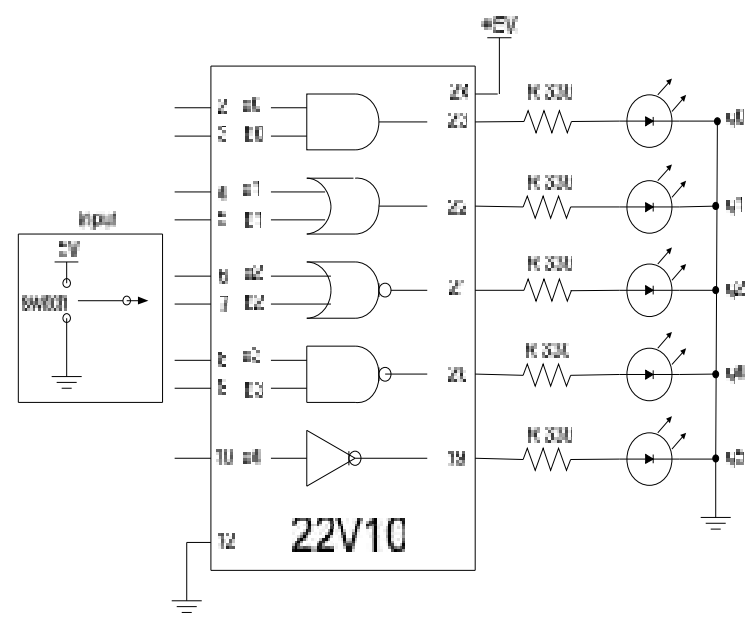

Gambar 4. Rangkaian IC PAL22V10 yang difungsikan sebagai gerbang logika

\section{Perancangan dan pembuatan software}

Perangkat software yang dirancang untuk sistim ini adalah perangkat lunak untuk menjalankan sistim trainer secara keseluruhan, software ini dirancang dengan menggunakan bahasa Warp 4.2.

\section{Gerbang Logika}

library ieee;

use ieee.std logic 1164.all;

entity gate is port $(a 0, a 1, a 2, a 3, a 4 \quad: \quad$ in std_logic;

$$
b 0, b 1, b 2, b 3 \quad: \quad \text { in }
$$

std_logic;

std_logic);

$$
q 0, q 1, q 3, q 4 \quad: \text { out }
$$

attribute part_name of gate :entity is "22V10",

attribute pin_numbers of gate :entity is "a 0:2 b0:3 a1:4 b1:5 a2:6 b2:7 a3:8 b3:9 a4:1 "q0:23 q1:22 q2:21 q3:20 q4:19";

end gate;

architecture behave of gate is begin

$$
\begin{aligned}
& q 0<=a 0 \text { and } b 0 ; \\
& q 1<=a 1 \text { or } b 1 ; \\
& q 2<=a 2 \text { nand } b 2 ; \\
& q 3<=a 3 \text { nor } b 3 ; \\
& q 4<=\text { not } a 4 ;
\end{aligned}
$$

end behave; 
Hasil Simulasi Gerbang Logika

Dasar

\section{Gerbang AND}

Tabel 1 Hasil pengujian gerbang AND

\begin{tabular}{|c|c|c|}
\hline B0 & A0 & Q0 \\
\hline 0 & 0 & 0 \\
\hline 0 & 1 & 0 \\
\hline 1 & 0 & 0 \\
\hline 1 & 1 & 1 \\
\hline
\end{tabular}

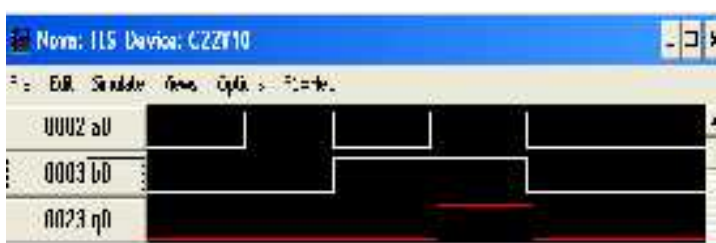

Gambar 5. Hasil simulasi gerbang AND

\section{Gerbang OR}

Tabel 2 Hasil pengujian gerbang OR

\begin{tabular}{|c|c|c|}
\hline B1 & A1 & Q1 \\
\hline 0 & 0 & 0 \\
\hline 0 & 1 & 1 \\
\hline 1 & 0 & 1 \\
\hline 1 & 1 & 1 \\
\hline
\end{tabular}

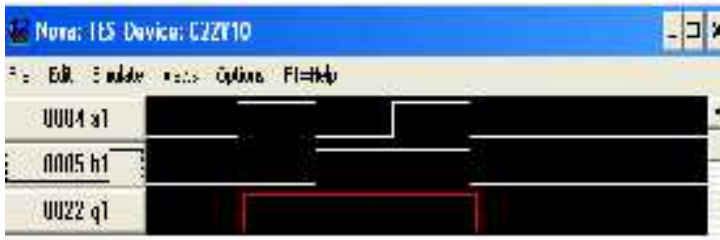

Gambar 6. Hasil simulasi gerbang OR

\section{Gerbang NOT}

Tabel 3 Hasil pengujian gerbang NOT

\begin{tabular}{|c|c|}
\hline A4 & Q4 \\
\hline 0 & 1 \\
\hline 1 & 0 \\
\hline
\end{tabular}

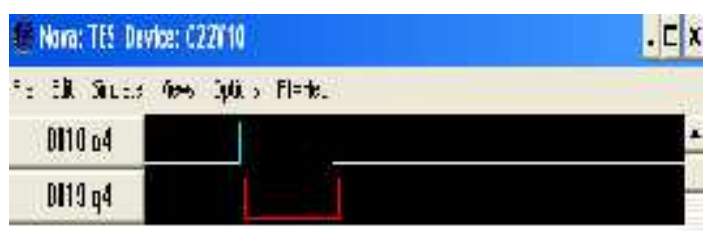

Gambar 7. Hasil simulasi gerbang NOT

\section{HASIL SIMULASI GERBANG LOGIKA KOMBINASIONAL}

\section{Gerbang NAND}

Tabel 4 Hasil pengujian gerbang NAND

\begin{tabular}{|c|c|c|}
\hline B2 & A2 & Q2 \\
\hline 0 & 0 & 1 \\
\hline 0 & 1 & 1 \\
\hline 1 & 0 & 1 \\
\hline 1 & 1 & 0 \\
\hline
\end{tabular}

\section{Gerbang NOR}

Tabel 5 Hasil pengujian gerbang NOR

\begin{tabular}{|c|c|c|}
\hline B3 & A3 & Q3 \\
\hline 0 & 0 & 1 \\
\hline 0 & 1 & 0 \\
\hline 1 & 0 & 0 \\
\hline 1 & 1 & 0 \\
\hline
\end{tabular}

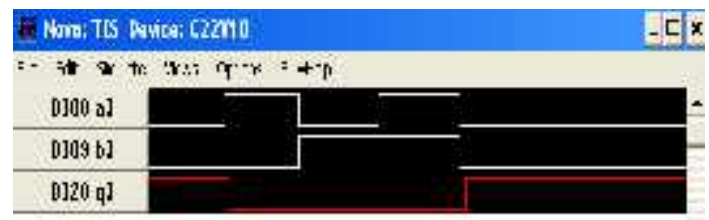

Gambar 8. Hasil simulasi gerbang NOR

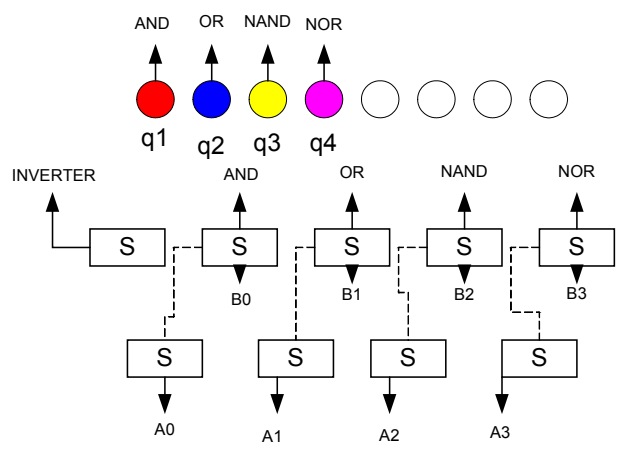

\section{ANALISA GERBANG LOGIKA DASAR}

Untuk percobaan test fisiknya, dipermudah dengan melihat konfigurasi pin sebagai berikut :

Dari konfigurasi di atas dapat terlihat bahwa untuk masing-masing gerbang: 


\section{Gerbang AND}

Switch yang dipakai sebagai input adalah S6(A0) dan S2(B0), dan outputnya adalah Q1. Berdasarkan teori gerbang AND, pada saat kedua input atau salah satunya yang diberikan bernilai rendah, maka keluarannya akan bernilai rendah. Dan hanya akan bernilai tinggi jika kedua inputnya bernilai tinggi. Hal ini telah dibuktikan pada simulasi dan test fisiknya. Untuk logikanya dapat dilihat pada table kebenaran dan penjelasan berikut:

$\mathrm{Q}=\mathrm{A}$. B (dinotasikan dengan "dan")

- $\mathrm{I}(\mathrm{A} 0)=0$

$\mathrm{I}(\mathrm{B} 0)=0$

Maka $\mathrm{O}(\mathrm{Q} 1)=0$

- $\mathrm{I}(\mathrm{A} 0)=0$

$\mathrm{I}(\mathrm{B} 0)=1$

Maka $\mathrm{O}(\mathrm{Q} 1)=0$

- $\mathrm{I}(\mathrm{A} 0)=1$

$\mathrm{I}(\mathrm{B} 0)=0$

Maka $\mathrm{O}(\mathrm{Q} 1)=0$

- $\mathrm{I}(\mathrm{A} 0)=1$

$\mathrm{I}(\mathrm{B} 0)=1$

Maka $\mathrm{O}(\mathrm{Q} 1)=1$

\section{Gerbang OR}

Untuk gerbang OR, switch yang digunakan sebagai inputannya adalah S7(A1) dan S3(B1). Sedangkan untuk keluarannya adalah Q2. Terlihat bahwa teori yang digunakan sangat mendukung percobaan yang dilakukan pada test fisiknya. Bahwa pada teori untuk gerbang OR dapat dijelaskan, keluarannya akan bernilai 0 (low) jika kedua input yang diberikan bernilai 0 (low), dan berbeda dengan gerbang AND, gerbang OR akan bernilai 1 (high) jika salah satu atau kedua inputannya bernilai 1 (high).

$\mathrm{Q}=\mathrm{A}+\mathrm{B}$ (dinotasikan dengan "atau")

$$
\begin{array}{ll}
\mathrm{I}(\mathrm{A} 1)=0 \\
\mathrm{I}(\mathrm{B} 1)=0 \\
\mathrm{Maka} \mathrm{O}(\mathrm{Q} 2)=0 \\
-\mathrm{I}(\mathrm{A} 1)=0 \\
\mathrm{I}(\mathrm{B} 1)=1 \\
\text { Maka } \mathrm{O}(\mathrm{Q} 2)=1
\end{array}
$$

- $\quad \mathrm{I}(\mathrm{A} 1)=1$

$\mathrm{I}(\mathrm{B} 1)=0$

Maka $\mathrm{O}(\mathrm{Q} 2)=1$

- $\mathrm{I}(\mathrm{A} 1)=1$

$\mathrm{I}(\mathrm{B} 1)=1$

Maka $\mathrm{O}(\mathrm{Q} 2)=1$

\section{Gerbang NOT}

Gerbang NOT merupakan negasi atau kebalikan dari inputnya. Jika input yang diberikan bernilai 1 (high) maka keluarannya akan bernilai 0 (low).

Logikanya dapat dinyatakan sebagai berikut:

- $\mathrm{I}(\mathrm{S})=0$

Maka $O(Q)=1$ atau sebaliknya

\section{ANALISA GERBANG LOGIKA KOMBINASIONAL}

\section{Gerbang NAND}

Gerbang NAND merupakan gerbang AND yang diinverterkan atau kebalikan dari gerbang AND, maksudnya pada saat kedua input atau salah satunya bernilai 0 (low) maka keluarannya akan bernilai 1 (high). Artinya keluarannya bernilai 0 (low) jika kedua inputannya bernilai 1 (high). Terlihat pada konfigurasi, switch yang digunakan untuk inputannya adalah S8(A2) dan S4(B2), sedangkan untuk keluarannya adalah Q3.

$\bar{Q}=\mathrm{A}$. B

- $\mathrm{I}(\mathrm{A} 2)=0$

$\mathrm{I}(\mathrm{B} 2)=0$

Maka O(Q3) = 1

- $\mathrm{I}(\mathrm{A} 2)=0$

$\mathrm{I}(\mathrm{B} 2)=1$

Maka O(Q3) = 1

- $\mathrm{I}(\mathrm{A} 2)=1$

$\mathrm{I}(\mathrm{B} 2)=0$

Maka O(Q3) = 1

- $\mathrm{I}(\mathrm{A} 2)=1$

$\mathrm{I}(\mathrm{B} 2)=1$

Maka $\mathrm{O}(\mathrm{Q} 3)=0$ 


\section{Gerbang NOR}

Gerbang NOR merupakan kebalikan dari gerbang NAND, dimana keluarannya akan bernilai 0 (low) jika salah satu atau kedua input yang diberikan bernilai 1 (high). Switch yang digunakan sebagai Input adalah S9(A3) dan S5(B3) dan outputnya adalah Q4.

$\bar{Q}=\mathrm{A}+\mathrm{B}$

- $\mathrm{I}(\mathrm{A} 2)=0$

$\mathrm{I}(\mathrm{B} 2)=0$

Maka $\mathrm{O}(\mathrm{Q} 3)=1$

- $\mathrm{I}(\mathrm{A} 2)=0$

$\mathrm{I}(\mathrm{B} 2)=1$

Maka $\mathrm{O}(\mathrm{Q} 3)=0$

- $\quad \mathrm{I}(\mathrm{A} 2)=1$

$\mathrm{I}(\mathrm{B} 2)=0$

Maka $\mathrm{O}(\mathrm{Q} 3)=0$

- $\mathrm{I}(\mathrm{A} 2)=1$

$\mathrm{I}(\mathrm{B} 2)=1$

Maka $\mathrm{O}(\mathrm{Q} 3)=0$

\section{KESIMPULAN}

Dengan menggunakan IC PAL 22V10 kita dapat mengaplikasikan teknologi Programmable Logic Device (PLD) untuk gerbang logika dasar AND, OR, NOT dan gerbang logika kombinasional NAND, NOR.

\section{DAFTAR PUSTAKA}

Brown, Stephen., 2000. Digital Logic of Fundamentals with VHDL Design, Singapore:MC.Graw-Hill

Cook, Nigel P., 2004 Practical Digital Electronics, Prentice Hall

Skahill, Kevin., 1997, VHDL for Programmable Logic, USA: Addison Wesley

Weste, Neil H.E., 2005.CMOS VLSI Design, USA: Addison Wesley 
ISSN: 2085-6989 